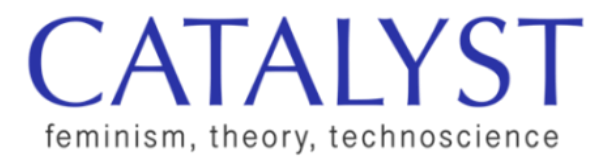

\title{
Book Review | Distributed Blackness: African American Cybercultures, by André Brock Jr. (NYU Press, 2020)
}

\author{
Jessica Sage Rauchberg \\ McMaster University \\ jess.rauchberg@gmail.com
}

In 2020, social media users around the world attempted to reckon with antiBlackness in internet cybercultures. Cybercultures are postracial entities that imagine a white, cisgendered male, non-disabled user in the global north (Nakamura 2013), while the "Black body [is] only legible through its perceived absence...from the material, technical, and institutional aspects of computers and society" (Brock 2020, 1). Despite efforts to center the heterogeneity of Black cultural experiences globally, focus from dominant media and entertainment institutions emphasize social media posts and data that foregrounded Black pain, suffering, and trauma. But what if Black aesthetics and performativity in a digital world did not hinge on white supremacist definitions of the human?

These inquiries drive the arguments and musings in André Brock Jr.'s Distributed Blackness: African American Cybercultures. The first part of the title-Distributed Blackness-refers to the "internetwork's capacity for discourse"(5) and demonstrates how hashtags and other algorithmic infrastructure are used to build and visualize Black political and social culture online. It is also an allusion to critical technocultural discourse analysis (henceforth CTDA), which Brock uses to disrupt and imagine beyond (white) Western digital cultural research practices. The subtitle, African American Cybercultures, speaks to the various ways Blackness and Black cultures are "performed...[and] absently embodied" (6) in online spaces. Examining the transformative roles of information and computer technologies (ICTs) in developing Black digital rhetorics and culture, Brock pursues an antiessentialist critical study of the networked relationships across various social media platforms that constitute Black cybercultures. 
Distributed Blackness is richly theoretical and interdisciplinary: the text draws from Black studies, ICT scholarship, critical/cultural approaches to communication and media, and Black feminist approaches to science and technology studies (STS). For Brock, merely studying hashtags, codes, or ICT hardware as singular entities does not properly illuminate upon the "transformative cultural philosophy of representation, technoculture, politics, and everyday life" (8). Brock's monograph foregrounds the ecological network of Black and African American cybercultures, such as Black Twitter, by presenting each chapter as a case study focusing on these heterogeneous nodes, a deliberate nod to the fragmented styles of reading in an era of information overload (127). CTDA departs from Western theorizations of the human to disrupt the essentialization of Black digital cultures. Distributed Blackness shows how Black and African American cybercultures evolve in different internet eras, tracing their unique collisions and departures for shaping digital performances of culture and identity. Enclaves such as Black Twitter emerge as networks of expressions, technological innovation, and philosophies centering Black life in a digital world.

Each chapter embraces Brock's commitments to expanding libidinal economy (Lyotard 1974). He uses CTDA to dissent from essentialism and emphasize Black agency in the digital sphere (10). Libidinal economy is related to affect but does not have a fixed, progressive state. It can be found in infrastructure and is "invisible to our perceptions just like the materials and processes of...[the] every day-until a rupture occurs" (10). For Brock, the libidinal economy is the clear differentiation between discourse and praxis and can circumvent white Western discourses of technological progress and innovation (11). His thinking through libidinal economy expands "nonwhite capacities for resistance" in cybercultures by grounding the book's overarching inquiry in Black pathos. Through this contextualization, readers imagine new possibilities for Black cybercultural epistemologies and digital communication practices that do not necessitate the (re)production of white supremacist logic. Noting how anti-Blackness is used as a signifying discourse that powers much of Western technoculture, Brock turns toward Afro-optimism to ask, what if technology embraced Black innovation and creation?

Chapter 1 is styled as a literature review and expands the author's previous work with critical technocultural discourse analysis as a methodology departing from Eurocentric theorizations of Blackness and knowledge-production. Brock contextualizes Black technoculture as a hypervisible network that disrupts "white, middle-class norms" (17). He notes that digital whiteness "operates as a...designation for [who has access to] people and humanity" (20). CTDA becomes an intervention that expresses "Blackness as a discursive, informational identity...that avoids the essentialization of Black culture" (25). Brock returns to his adaptation of the postmodern libidinal economy to demonstrate how "racial ideologies power digital practice" (31). He brings this thinking into the latter half 
of the book in his analyses of ratchetry and respectability on Black Twitter. Chapter 1's literature review situates jouissance as a technology for Black digital data that embodies desire and local Black American cultural practices. Blackness emerges as an informational identity despite the prominence of white supremacist design in ICT infrastructure.

Chapter 2 examines the foundation of now-defunct Blackbird, a niche internet web browser targeted at Black and African American users in the late 2000 . Asking if Blackness "can be discerned at the level of digital infrastructure" (38), Brock uses CTDA to assess how Blackbird helped to build both in-and-out-group perspectives on racial identity formation and technoscientific practices. Here, Brock's established commitment to study digital artifacts beyond tweets and user posts shines. His analysis demonstrates how Blackbirds' infrastructure allows for its creators to imagine a browser that does not reify white supremacist ideas of "rationality" or information gathering. Brock's CTDA of Blackbird also examines cultural bloggers' reviews of the browser. The reviews function as paratexts and reveal the complex intricacies of how values enact performativity between user, ideology, and data from different ICTs. Brock's finding in Chapter 2 aligns with breaking research in postcolonial media studies (Shome 2016), which similarly addresses alternative ways of ICT development and usage outside of a white or Western context, recontextualizing how technology shapes cultures both on and offline.

Chapters 3, 4, and 5 collectively present a rich, in-depth consideration of Black Twitter. Chapter 3 examines Twitter as a hub for Black techno-cultural enactment (80). Uniting discussion from the previous chapters with a broad overview of Twitter's infrastructure, Brock brings in Catherine Squires's (2002) work on Black and African American satellite publics to analyze how alternate ideologies influence social networking enclaves. He likewise positions Black Twitter as a "digital/virtual space where Blackness frames the politics of the everyday, occasionally...breaking free to confront or simply inform wider publics" (88). Chapters 4 and 5, respectively, analyze ratchetry as a digital practice to counteract racism and respectability: nodes of tension that build the complex networks of Black Twitter discourse. Brock initially restyles ratchetry as positive, digital energetic practices that emerge from a "militant willingness to perform Blackness" (129) in digital spaces that still conceptualize the ideal user as a white American. Ratchetry is inherently playful; for example, Brock discusses a Black Twitter user's viral 2016 Change.org petition that called for trap artist Fetty Wap to perform at Nancy Reagan's funeral: a commentary on the Reagan administration's criminalization of Black Americans (147).

Black Twitter users also employ reflexive digital practice alongside ratchetry to dissent from the omnipresence of anti-Black racism online-often with different paraverbal technologies like humor, sensuality, or anger (150). Brock presents a 
detailed analysis of the viral Twitter hashtag, \#ThanksgivingWithBlackFamilies, which used multimodal texts (pictures, GIFs, and other memetic artifacts) to build playful digital relational practices and community building beyond anti-Blackness (170). Technologies like Twitter and other social media networks challenge the prominence of digital respectability politics threaded throughout Chapter 5 . As respectability politics influence offline and online surveillance of Black users, ratchetry and reflexive digital practice imagine new ways of digital performance.

Finally, Chapter 6's conclusion weaves Brock's larger inquiry together, bringing in Afrofuturism to importantly argue how Black joy and pleasure can reroute understandings of Black data creation. Brock is clear and succinct with his questions: What does it mean to imagine Black technocultures away from a model of deficit (241)? How can we imagine other ways of creating, connecting, and collectively building through technologies like the internet? And what if the socialtechno study of digital Blackness prioritized the understanding of Black joy, humor, and styles of communication that expand beyond trauma? Distributed Blackness shares an important connection with other scholarship in Black feminist STS, crip technoscience, and postcolonial media studies, and is certain to have a transformative impact on scholars and artists working in these areas. Most importantly, Brock's theorization of Black technocultures may not articulate how to place a band-aid over the internet's anti-Blackness-instead, it may take us somewhere better.

\section{References}

Lyotard, Jean-François. 1974. Libidinal Economy. Bloomington: Indiana University Press.

Nakamura, Lisa. 2013. Cybertypes: Race, Ethnicity, and Identity on the Internet. New York: Routledge.

Shome, Raka. 2016. "When Postcolonial Studies Meets Media Studies." Critical Studies in Media Communication 33 (3): 245-63.

https://doi.org/10.1080/15295036.2016.1183801.

Squires, Catherine R. 2002. "Rethinking the Black Public Sphere: An Alternative Vocabulary for Multiple Public Spheres." Communication Theory 12 (4): 446-68. https://doi.org/10.1111/j.1468-2885.2002.tboo278.x.

\section{Author Bio}

Jessica Sage Rauchberg is a doctoral candidate in the Department of Communication Studies and Media Arts at McMaster University. Using critical/cultural studies, Jess's research is focused on developing crip, neuroqueer, and disability justice approaches to studying algorithmic oppression in digital cultures. 